\title{
Establishment of clonal myogenic cell lines from severely affected dystrophic muscles - CDK4 maintains the myogenic population
}

\author{
Guido Stadler ${ }^{1}$, Jennifer CJ Chen², Kathryn Wagner ${ }^{3}$, Jerome D Robin', Jerry W Shay ${ }^{1}$, Charles P Emerson Jr Jr², \\ Woodring E Wright ${ }^{1 *}$
}

\begin{abstract}
Background: A hallmark of muscular dystrophies is the replacement of muscle by connective tissue. Muscle biopsies from patients severely affected with facioscapulohumeral muscular dystrophy (FSHD) may contain few myogenic cells. Because the chromosomal contraction at $4 q 35$ linked to FSHD is thought to cause a defect within myogenic cells, it is important to study this particular cell type, rather than the fibroblasts and adipocytes of the endomysial fibrosis, to understand the mechanism leading to myopathy.

Results: We present a protocol to establish clonal myogenic cell lines from even severely dystrophic muscle that has been replaced mostly by fat, using overexpression of CDK4 and the catalytic component of telomerase (human telomerase reverse transcriptase; hTERT), and a subsequent cloning step. hTERT is necessary to compensate for telomere loss during in vitro cultivation, while CDK4 prevents a telomere-independent growth arrest affecting CD56 + myogenic cells, but not their CD56- counterpart, in vitro.

Conclusions: These immortal cell lines are valuable tools to reproducibly study the effect of the FSHD mutation within myoblasts isolated from muscles that have been severely affected by the disease, without the confounding influence of variable amounts of contaminating connective-tissue cells.
\end{abstract}

\section{Background}

Most muscular dystrophies result from a defect within myogenic cells that leads to progressive muscle weakness and wasting, and in severe cases, to the replacement of muscle fibers by connective tissue and/or fat. At advanced stages, skeletal muscle is replaced by fibroblasts and adipocytes. Although these cell types probably promote disease in later stages, it is generally believed that the root cause leading to most muscular dystrophies is a defect originating in myogenic cells. We therefore developed a protocol to enrich, immortalize and isolate rare muscle progenitor cells from severely affected dystrophic muscles to obtain clonal myogenic cell lines. In this report, the protocol is described for cells isolated from skeletal muscle of people with facioscapulohumeral muscular dystrophy

\footnotetext{
* Correspondence: Woodring.Wright@UTSouthwestern.edu 'Department of Cell Biology, UT Southwestern Medical Center at Dallas, Dallas, TX, USA

Full list of author information is available at the end of the article
}

(FSHD), but the technique is also applicable to other muscular dystrophies.

FSHD has been linked to deletions of D4Z4 tandem repeats at chromosome 4q [1], but it is still unclear how this deletion causes disease. Primary skeletal-muscle cultures have been used in attempts to model the disease, and several FSHD-specific phenotypes, such as increased vacuolization and sensitivity to oxidative stress [2] have been described. In addition, there have been reports describing incorrect expression of various FSHD candidate genes in muscles and myogenic cells from patients with FSHD, including FSHD region gene (FRG) 1 and the double homeobox (DUX)4 gene [3-6]. However, in many instances, these findings have not been consistent between different laboratories, perhaps as a result of variables such as muscle type, disease progression, culture purity, in vitro culture conditions or replicative age of the cells. In particular, because of their low replicative potential, it is difficult to use the same purified primary cultures for multiple large-scale experiments in different 
laboratories to reproduce the findings with the same material. Immortal cell lines provide a solution to this problem, and are a useful and unlimited resource for the research community.

To immortalize FSHD muscle-derived myogenic cells, we used the same strategy as previously described for normal skeletal-muscle cells; that is, ectopic expression of human telomerase reverse transcriptase (hTERT) to overcome replicative senescence, and of CDK4 to block the growth arrest due to cellculture stress (stress or aberrant signaling-induced senescence (stasis)) [7]. Replicative senescence is an irreversible growth arrest triggered by a DNA damage signal from critically short telomeres $[8,9]$. Telomere shortening occurs during each cell division, because of the end replication problem [10], end processing [11] and oxidative damage [12], and can be prevented by addition of telomeric repeats by the reverse transcriptase telomerase $[13,14]$. Overexpression of hTERT, the catalytic subunit of telomerase, has been shown to prevent senescence of a variety of human somatic cells that do not express this gene endogenously [15-17]. However, inadequate in vitro culture conditions can cause accumulating stress to certain cell types, which may lead to stasis, a premature growth arrest independent of telomere length. We have shown that overexpression of CDK4 is able to bypass stasis in many cell types, including myoblasts, while maintaining normal phenotypes and cell cycle control $[7,18]$. We show in this paper that overexpression of CDK4 delays or even prevents overgrowth of myogenic CD56+ cells by their non-myogenic CD56counterparts, and therefore facilitates the isolation of clonal myogenic cell lines from severely affected dystrophic muscles.

\section{Results}

Primary cultures from severely affected FSHD muscles primarily consist of non-myogenic cells

During progression of FSHD, the muscle fibers of certain skeletal muscles are progressively replaced by connective tissue. The biceps is one of the muscles preferentially affected by FSHD (Figure 1A). Despite good strength in the biopsied biceps, muscle fibers from the biceps of a 42-year-old man with FSHD (subject 01A) were found to be in close association with fibrotic tissue and surrounded by large pockets of adipose cells. By contrast, the biceps muscle from his 46-year-old healthy brother (subject $01 \mathrm{U}$, inset) exhibited no endomysial fibrosis, and was virtually free of adipocytes. The percentage of myogenic cells in the primary cell cultures from the biceps muscle of 01A (designated 01Abic) was only $20 \%$, and decreased rapidly during in vitro cultivation (Figure 1B). We used CD56 to identify myogenic cells and validated this by several observations. First, CD56+ and CD56- cells were distinct and stable populations (Figure 1C), and skeletal-muscle cells did not switch between a CD56+ and CD56- phenotype. Second, CD56+, but not CD56- cells, expressed the intermediate filament protein, desmin, another marker of skeletalmuscle cells (Figure 1D). Third, purified CD56+ but not CD56- populations fused into multinucleated myotubes when changed to differentiation medium (Figure 1E).

\section{CDK4 maintains the myogenic population}

To test the hypothesis that stasis of CD56+ cells is responsible for their overgrowth by CD56- cells in vitro, we infected primary 01Abic cells with a retrovirus containing CDK4 at the fifth population doubling (PD5), when the fraction of CD56+ cells was about $20 \%$. Whereas the percentage of CD56+ cells quickly dropped towards zero in uninfected cells (Figure 2A, blue line with yellow circles), CDK4 overexpression maintained the CD56+ cells at roughly $20 \%$ for an additional 50 days, corresponding to about 25 PDs (Figure 2A, blue line with blue squares). The effect of CDK4 on maintenance of the CD56+ population was also dramatic in the primary cells cultured from the $01 \mathrm{U}$ biceps (designated 01Ubic) (Figure 2A, red lines). At early PDs, this cell strain consisted of a seemingly pure myogenic population, which nonetheless was overgrown by initially rare CD56- cells (Figure 2A, red line with yellow circles) at between 30 and 50 days of culture. CDK4 overexpression prevented this overgrowth, and maintained the CD56+ population for the entire culture period (Figure $2 \mathrm{~A}$, red line with red squares). These experiments suggest that CDK4 overexpression confers a selective growth advantage on CD56+ cells compared with their CD56- counterparts. This hypothesis was confirmed by infection of CD56 sorted 01Abic cells with CDK4 (Figure 2B). Overexpression of CDK4 led to a doubling of the replicative lifespan of CD56+ cells, from about 40 to 80 PDs. In the absence of CDK4, the growth rate of the CD56+ cells began to slow down as early as PD20, contributing to the overgrowth by CD56- cells long before the CD56+ cells actually had their growth arrested. By contrast, CDK4 had only a minor effect on the lifespan of CD56- cells. Telomeres of CD56- cells were shorter than those of their CD56+ counterparts at growth arrest in the absence of CDK4, consistent with the interpretation that CD56- cells arrested because of replicative aging, whereas CD56+ cells arrested because of stasis before reaching the telomere-based replicative limits. CDK4 overexpression led to further telomere shortening during the increased lifespan of the CD56+ population, reaching lengths similar to those of the senescent CD56- population when they finally became senescent (not shown). 


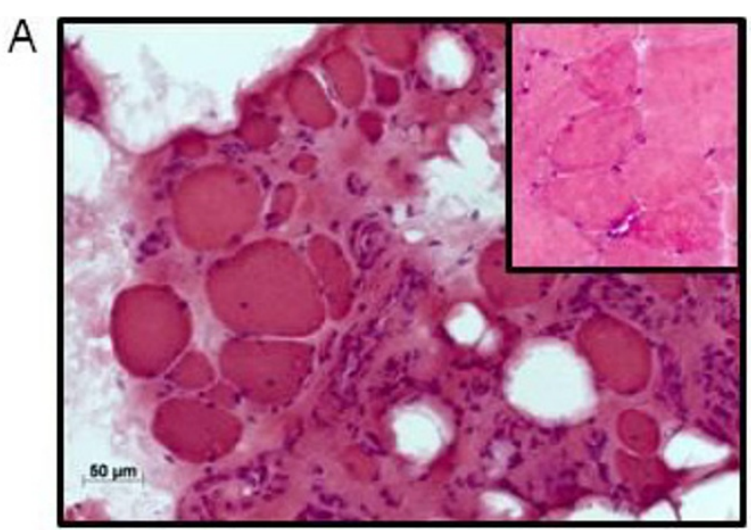

B

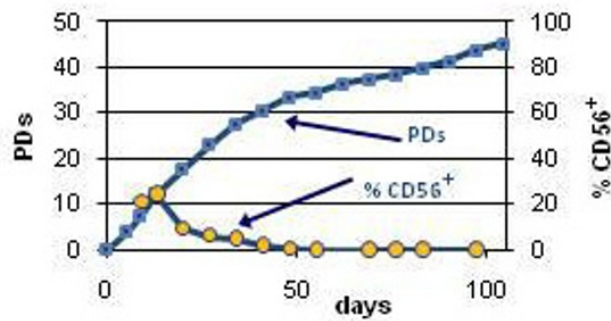

C

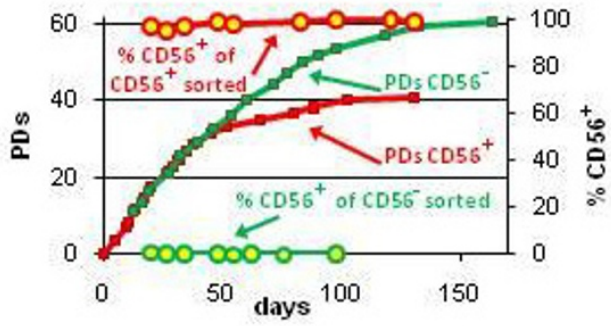

D
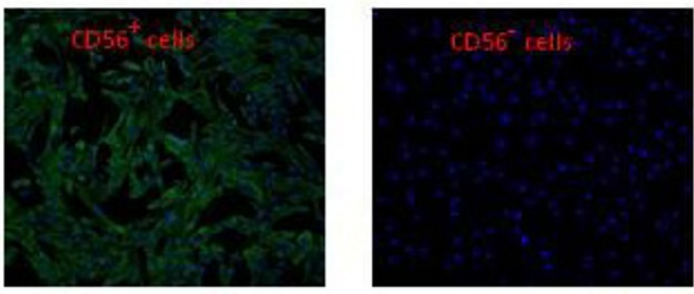

E
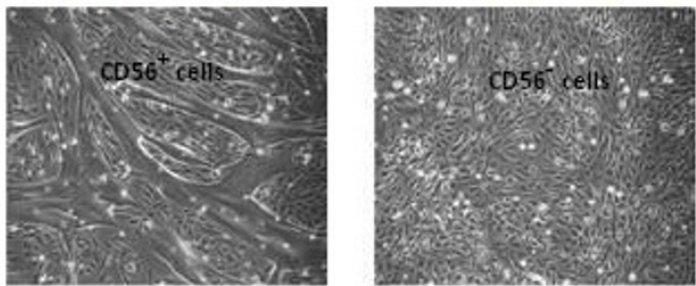

Figure 1 Replacement of FSHD muscle by non-myogenic cells. (A) Transverse section of the biceps muscle from subject $01 \mathrm{~A}$ with facioscapulohumeral muscular dystrophy (FSHD), showing extensive fibrosis and large pockets of adipocytes; muscle fibers displayed variable diameter. By contrast, biceps muscle from his brother (subject $01 \mathrm{U}$, inset) had a relatively uniform array of myogenic fibers with no endomysial fibrosis or fatty infiltration. Hematoxylin and eosin, original magnification 20 ×. (B) Percentage of CD56+ cells in primary cell cultures isolated from FSHD biceps muscle shown in (A) during in vitro cultivation. PD = population doubling. (C) Growth curves of sorted CD56+ (red squares) and CD56- (green squares) populations from the primary 01A biceps cell culture. The percentage of CD56+ cells in sorted, CD56+ and CD56cultures over time are also displayed (circles outlined in red (CD56+) or green (CD56-)). (D) Desmin immunostaining (green) of sorted CD56+ and CD56- cells. Nuclei were counterstained with 4',6-diamidino-2-phenylindole (blue). (E) Sorted CD56+ and CD56- cells after 3 days in differentiation medium. 

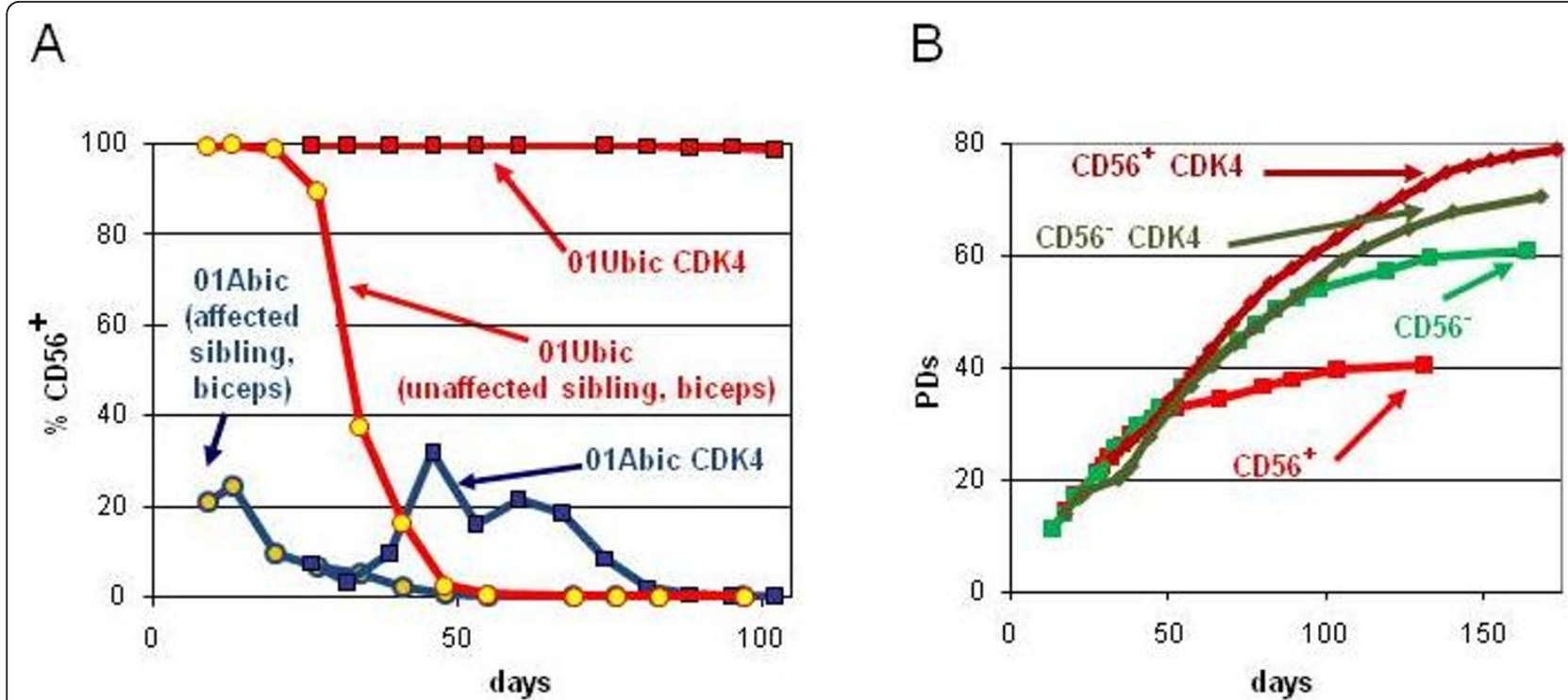

Figure 2 CDK4 maintains the myogenic population. (A) Percentage of CD56+ cells in primary cultures from biceps muscle of a subject with facioscapulohumeral muscular dystrophy (FSHD) (01Abic) and his unaffected brother (01Ubic) with and without overexpression of CDK4. (B) Growth curves of CD56 sorted 01Abic cells with and without overexpression of CDK4.

\section{Myogenic clones uniformly expressing CD56 can be isolated after immortalization of primary cultures consisting mainly of CD56- cells}

Even though pure myogenic populations can be isolated from mixed primary cultures using antibody based methods, such as fluorescence or magnetic-activated cell sorting (FACS or MACS), those cells have a very restricted replicative lifespan, and therefore can be used for only a limited number of experiments. We thus established the following protocol to isolate immortal clonal myogenic cell lines from severely affected dystrophic muscle. Primary cultures (in this case, 01Abic, containing only $20 \%$ CD56+ cells) were consecutively infected with retroviruses for overexpression of CDK4 and hTERT, and then uniformly CD56-expressing clones were isolated (Figure 3A). In our hands, differences in viral titers, multiplicity of infection (MOI) and virus type have not had significant effects on rate of immortalization, and we have obtained similar results using low MOI retroviruses or high MOI lentiviruses. For the experiments published here, about $1 \%$ of the cells survived selection and therefore had been transduced, corresponding to an MOI of $\sim 0.01$. As CDK4 expression maintains the myogenic population, the immortal population had an increased and stable percentage of CD56+ cells after drug selection compared with the parental population at the same time point (14\% vs. $2 \%$ ), and no sorting step before infection was necessary to isolate myogenic clones, which could be carried out easily and with little effort. Healthy-looking and well-separated clones were picked, roughly $90 \%$ of which survived the subsequent expansion to the $\sim 2 \times$ $10^{6}$ cells necessary for cryopreservation and analysis for myogenicity (CD56 expression and fusion competence). Of 15 randomly analyzed clones, four (27\%) were myogenic. The higher percentage of myogenic clones than CD56+ cells in the immortal population (27\% vs. 14\%) is consistent with the observed growth advantage for CD56+ over CD56- cells at clonal density (data not shown). Growth curves of three immortal myogenic clones are shown in Figure $3 \mathrm{C}$, in comparison with the CD56 sorted primary culture, with and without CDK4. Immortalized myoblasts had a doubling time of about 24 to 30 hours, which we found was only slightly higher than that of primary cultures at early PDs $(\sim 20$ to 26 hours). All clones underwent $>200$ PDs without any sign of growth retardation. Whereas telomere restriction fragment analysis showed that telomeres were extended by ectopic hTERT for most myoblast clones (Figure 3B, immortal clone number 6 as a representative example), some clones maintained telomere lengths at levels similar to that of the primary culture (Figure 3B, compare immortal clone number 2 with the primary CD56+ population). The different telomere dynamics may be due to a variety of factors, including hTERT integration site-specific hTERT transcription, or differences in factors affecting telomerase enzyme assembly, recruitment or activity at telomeres.

All immortal clones stably expressed CD56 and desmin, and retained their ability to fuse into myosinexpressing, multinucleated myotubes when moved to differentiation medium (Figure 4, 01Abic immortal 


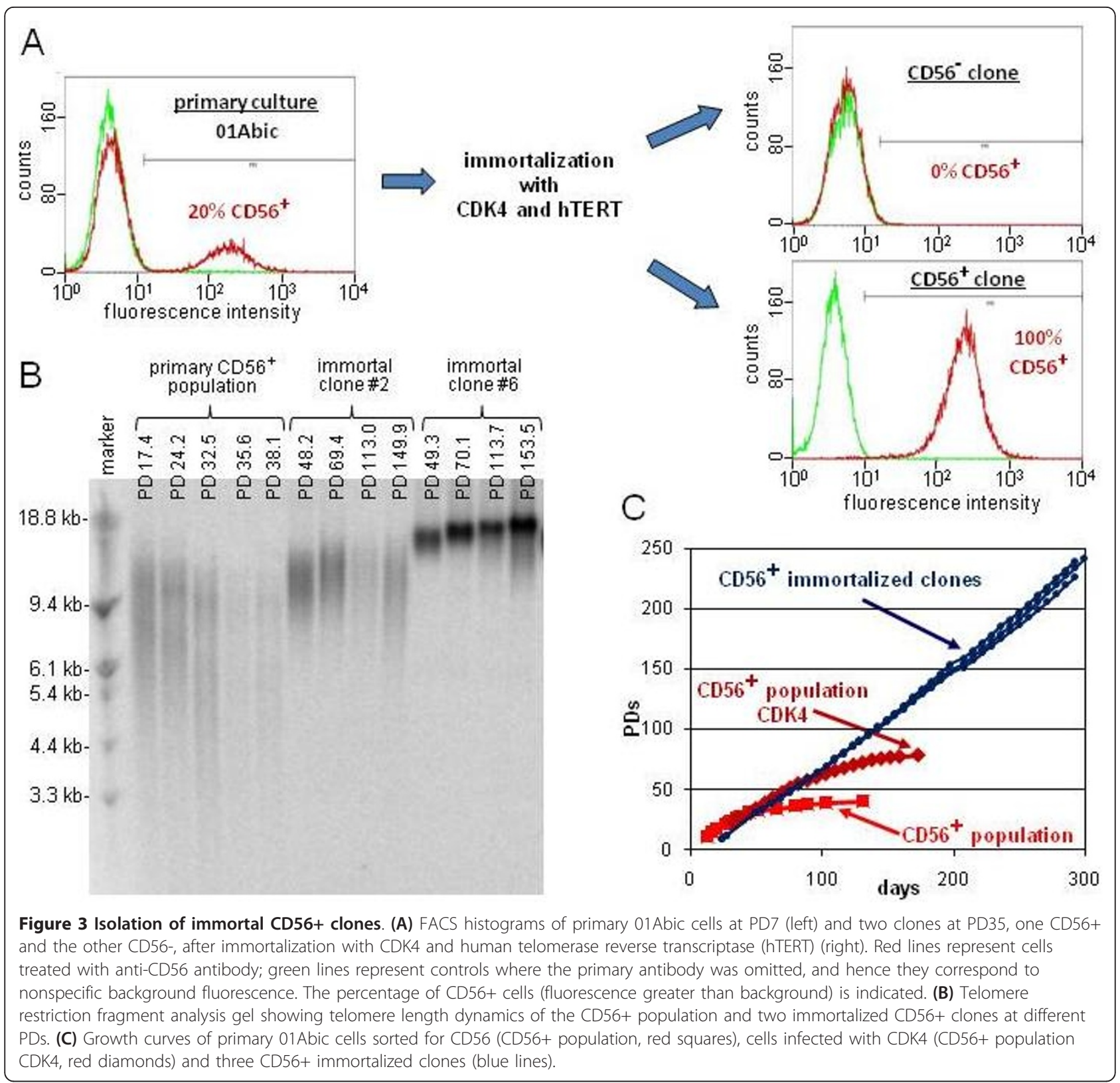

clone number 6 is shown as a representative example); however, the differentiation kinetics were found to slow down with time in culture. Immortal clones at early PDs (Figure 4, PD35) readily formed very large myotubes after only 3 days in differentiation medium; 70\% of nuclei were present in multinucleated and/or myosinpositive cells, detected by immunostaining with MF20 antibody. By contrast, after $>100$ PDs (Figure 4, PD120 and PD234), fusion was delayed and resulting myotubes were thinner, with $<10 \%$ of nuclei present in MF20positive cells on day 3 , and approximately $50 \%$ (PD120) and 30\% (PD234) appearing in multinucleated/MF20positive cells at day 7 .

\section{Discussion}

Since the description of the first cancer cell line [19], infinitely growing human cell lines have been invaluable tools in biology. In contrast to most cancer cells that are immortal, human somatic cells have a finite lifespan and have to be 'immortalized' to obtain unlimited proliferative capacity. Historically, this was initially achieved by overexpression of viral oncogenes such as simian virus (SV) 40 [20], which is always associated with at least some degree of neoplastic transformation. By contrast, hTERT overexpression not only immortalizes a variety of human primary cultures, but has been reported to do this while also maintaining the cellular 


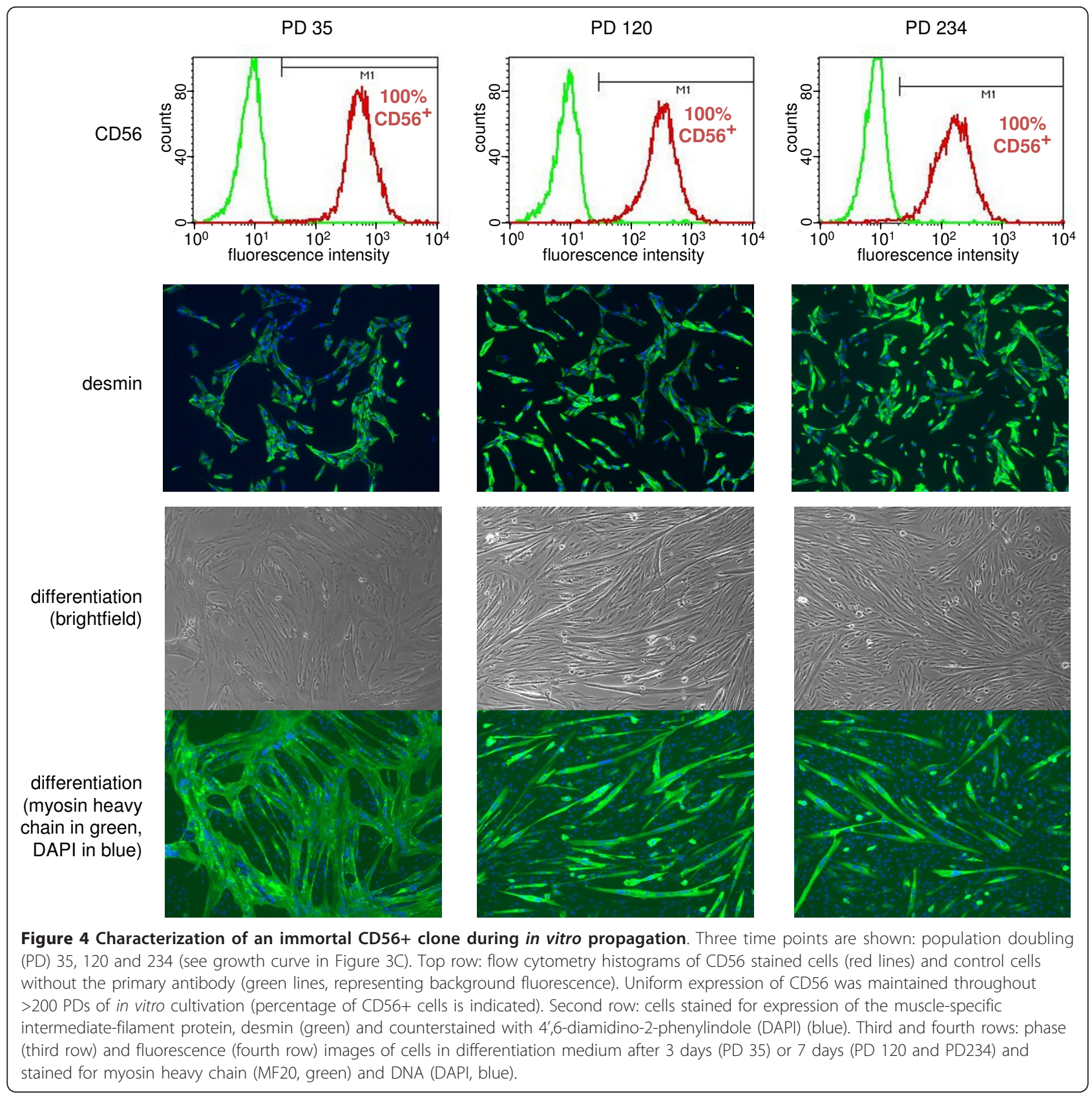

phenotype $[15,21,22]$. However, this latter notion has been challenged by the observation of putative non-telomeric activities of hTERT [23-25], with strong evidence for its potential to modulate the Wnt pathway in mice [26]. In most myoblast clones, expression of hTERT for just a few PDs is sufficient to elongate telomeres by several kilobases (Figure 3C, clone number 6). Although the importance of the Wnt pathway in skeletal-muscle differentiation is well documented [27], we have not found any obvious phenotypic change between the hTERT-expressing cells described here and cell models that only transiently overexpress hTERT before Cre recombinase-mediated excision of the hTERT cassette (Stadler and Wright, unpublished data). The slower differentiation kinetics and formation of thinner myotubes seen in high passage hTERT cells (Figure 4) were not due to a direct effect of ectopic hTERT, as this phenotype was not seen with lower passage cells, in which hTERT had already been expressed for $>20$ PDs. We suggest that this change in differentiation kinetics is instead due to prolonged in vitro cultivation and its associated potential for epigenetic drift and constant selection for proliferation. Hence, it is crucial to take the replicative history of a cell into account, even for 
immortal cell lines, and to perform parallel analyses only on cell lines at roughly similar PD levels. In situations where this is not practical, it may be necessary to confirm that myogenic potential and differentiation kinetics have not changed with additional culturing. These are also important variables to consider when comparing different cell lines and cell clones with one another. Although there may be insertion-specific variation, our findings link changes in the differentiation ability of a cell line with the time spent by that cell line in culture.

The conditions for immortalization of human myoblasts were initially established using primary cultures from the pectoralis major muscle [7]. In addition to cell-culture supplements, such as dexamethasone and hepatocyte growth factor, ectopic CDK4 was necessary to prevent telomere-independent growth arrest (stasis). Fetal lung fibroblasts require the spin-trap compound ntert-butyl hydroxylamine in addition to low oxygen to avoid stasis [28], but this substance was extremely toxic to myoblasts (unpublished observations). This might reflect the consequences of blocking nitric oxide signaling in myoblasts [29].

In fetal fibroblasts and epithelial cells, stasis is often associated with an increase in p16 [18,28], and therefore ectopic expression of CDK4 was chosen to titer out the upregulation of this cell cycle inhibitor. Whereas others have shown that p16 is increased in growth-arresting myoblasts [30], we found that p16 levels are not increased in human myoblasts during stasis [7]. Differential regulation of cell cycle inhibitors in vitro may be explained by different culture conditions, or by developmental differences of fetal versus adult myoblasts (used in the former and latter studies, respectively), as has been shown for fibroblasts [28]. We are currently investigating which factors prevent adult myoblasts from being immortalized by hTERT in the absence of CDK4 and are hence responsible for stasis.

In contrast to CD56+ myoblasts, CD56- cells did not exhibit stasis under our culture conditions, which were originally optimized for myoblasts. This is supported by the following observations: First, CDK4 overexpression in CD56- cells did not lead to a significant increase in their proliferative potential. Second, CD56- cells could be immortalized by hTERT alone in conditions of low oxygen (data not shown), suggesting that CD56+ cells are more vulnerable to 'stress' (which triggers stasis) compared with CD56- cells, and therefore CD56- cells may have a growth advantage in 'stressful' situations, such as during pathological regeneration of muscle in vivo. Additionally, it seems that at low passage, sorted CD56+ cells have growth rates similar to those of CD56-, whereas the former are rapidly overgrown when unsorted, arguing that CD56- cells might inhibit growth of CD56+ cells. One candidate for this inhibitory activity is myostatin, which has been shown to be expressed by both skeletal-muscle fibroblasts and myoblasts [31], and to inhibit proliferation of myoblasts [32]. Our immortalized CD56+ and CD56- clones from skeletal muscle provide a model system to study the relationship between them and to help elucidate the intercellular crosstalk and regulatory pathways between different cell types.

Although we cannot exclude the possibility that primary cultures from skeletal muscle contain non-myogenic CD56+ cells, such as infiltrating immune cells [33], all CD56+ immortal clones analyzed to date in our laboratory $(>20)$ were desmin-positive and fusioncompetent.

\section{Conclusions}

In summary, we describe a simple and efficient protocol to establish immortal myogenic cell lines from dystrophic muscle that consists mainly of non-muscle tissue. Additionally, we provide evidence that stasis of myoblasts and not their CD56- counterpart is responsible for overgrowth of the former by the latter in primary cultures, which can be prevented by ectopic CDK4. To our knowledge, this is the first report of immortal myogenic human cell lines harboring the FSHD mutation, and will be useful in investigating this enigmatic disease.

\section{Methods}

The study was approved by The Johns Hopkins Medicine Institutional Review Board.

\section{Human subjects and tissue collection}

The male proband (subject 01A) first exhibited weakness in the legs as a teenager. At time of enrollment, he was 42 years old, and exhibited mild facial weakness, scapular winging and asymmetric weakness in the limbs, consistent with the FSHD phenotype. Molecular diagnosis of FSHD was confirmed by the University of Iowa Diagnostic Laboratories, which identified a HindIII 4qA allele of $26 \mathrm{~kb}$ in length. An open muscle biopsy was taken from the biceps muscle (01Abic), which had its strength rated as $4+$ out of 5 on the modified Medical Research Council scale. Tissue was also obtained from the biceps muscle (01Ubic) of the proband's 46-year-old brother $(01 \mathrm{U})$, who had full muscle strength and no disease allele found on gene testing. Approximately $300 \mathrm{mg}$ of tissue was reserved for histological and biochemical assays, and $\sim 500$ to $700 \mathrm{mg}$ tissue was used for primary cell isolation.

\section{Primary cell isolation and cell culture}

The biceps muscle tissue was minced into fragments of $<5 \mathrm{~mm}^{2}$, and stored at $4^{\circ} \mathrm{C}$ in a Ham's F10 medium containing 20\% fetal bovine serum (FBS; Hyclone, Thermo 
Scientific, Logan, UT, USA), 2\% chick embryo extract and $2.5 \mathrm{ng} / \mathrm{ml}$ basic fibroblast growth factor (Biopioneer, San Diego, CA, USA), supplemented with 1\% antibiotic/ antimycotic (Cellgro, Manassas, VA, USA) until processed for cell isolation (within approximately 24 hours of biopsy) (viable cells have been successfully isolated from tissues stored in this manner up to 6 days after biopsy). Tissue was cleaned and minced in Hanks' balanced salt solution (HBSS, catalogue number 14175; Gibco, Grand Island, NY, USA) and dissociated in $5 \mathrm{ml}$ of enzyme solution ( $1 \mathrm{mg} / \mathrm{ml}$ collagenase IV, $2.4 \mathrm{U} / \mathrm{ml}$ dispase (both Worthington, Lakewood, NJ, USA) and $2.5 \mathrm{mmol} / \mathrm{l} \mathrm{CaCl}_{2}$ in HBSS] for 45 minutes at $37^{\circ} \mathrm{C}$, triturating every 15 minutes with a $5 \mathrm{ml}$ serological pipette (moving it up and down $\sim 10$ to 15 times), and filtered through $100 \mu \mathrm{m}$ and $40 \mu \mathrm{m}$ cell sieves (BD Biosciences, Bedford, MA, USA). Cells were pelleted by spinning in a centrifuge at $1000 \mathrm{~g}$ for 5 minutes, and resuspended in $2 \mathrm{ml}$ growth medium (Ham's F-10 supplemented with $20 \%$ FBS (Hyclone), 0.5\% chick embryo extract, 1.2 $\mathrm{mmol} / \mathrm{l} \mathrm{CaCl}_{2}$ and $1 \%$ antibiotic/antimycotic (Cellgro), prepared as fresh stock at least every 7 days) and counted with a hemocytometer. The $01 \mathrm{Abic}$ cells were seeded in $2 \mathrm{ml}$ growth medium on a $35 \mathrm{~mm}$ gelatincoated dish, and the 01Ubic cells were seeded on a 60 $\mathrm{mm}$ dish in $5 \mathrm{ml}$ growth medium. Cells were cultured undisturbed for 48 hours, after which they were given fresh growth medium daily for 2 to 4 days. When approximately 50 to $70 \%$ confluent, cells were treated with trypsin (TrypLE Express/Gibco) for 5 minutes at $37^{\circ} \mathrm{C}$, neutralized with an equal volume of growth medium, and counted with a hemocytometer. For expansion, cells were seeded at $\sim 2000$ to 3000 cells $/ \mathrm{cm}^{2}$ in growth medium. For freezing, an equal volume of ice-cold $2 \times$ freezing medium (20\% dimethysulfoxide, 50\% FBS, 30\% growth medium) was added to cells and mixed well, then cells were incubated in the liquid nitrogen vapor phase for at least 1 hour before storage at $-140^{\circ} \mathrm{C}$.

To standardize conditions for growth of primary and immortalized cells, primary myoblasts were subsequently cultured in a 4:1 mixture of Dulbecco modified Eagle medium (DMEM) and Medium 199 (Hyclone), supplemented with 15\% FBS (Hyclone), 0.02 M HEPES buffer, $1.4 \mathrm{mg} / \mathrm{l}$ vitamin B12 (both Sigma-Aldrich, St. Louis, MO, USA), $0.03 \mathrm{mg} / \mathrm{ZnSO}_{4}$ (Fisher Scientific, Fair Lawn, NJ, USA), $0.055 \mathrm{mg} / \mathrm{l}$ dexamethasone (SigmaAldrich), $2.5 \mu \mathrm{g} / \mathrm{l}$ hepatocyte growth factor (Chemicon International, Temecula, CA, USA) and $10 \mu \mathrm{g} / \mathrm{l}$ basic fibroblast growth factor (BioPioneer), on dishes coated with $0.1 \%$ pigskin gelatin (Sigma-Aldrich) in a $2-5 \%$ oxygen environment [34]. Hepatocyte and fibroblast growth factors were added to a volume of medium that was used within 1 week. Cells were routinely grown in 100 $\mathrm{mm}$ tissue culture dishes (BD Falcon, Franklin Lakes,
NJ, USA) covered by $10 \mathrm{ml}$ medium, with a weekly medium change if cells were not passaged before that (usually one passage every 5 to 7 days). Cells were passaged at 50 to $90 \%$ confluency using $0.05 \%$ trypsin/ EDTA (Gibco), and cell numbers determined (Z1 Coulter Particle Counter; Beckman Coulter, Miami, FL, USA). PD was calculated using the formula: $P D=\ln$ [(final number of cells)/(initial number of cells)]/In(2).

For differentiation, $1.2 \times 10^{5}$ myoblasts were seeded in six-well dishes, then 24 hours later, cells were washed twice with phosphate-buffered saline (PBS) and fed with differentiation medium (DMEM and Medium 199 in a ratio of $4: 1$, supplemented either with $2 \%$ horse serum (Gibco) or with $0.02 \mathrm{~mol} / \mathrm{l}$ HEPES plus $10 \mathrm{mg} / \mathrm{l}$ insulin and $100 \mathrm{mg} / \mathrm{l}$ apo-transferrin (both Sigma-Aldrich)). Results obtained were similar with both differentiation media, although a delay of $\sim 1$ day was observed with horse serum relative to insulin/transferrin.

\section{Retroviral infection}

The construction of the vectors used for immortalization (CDK4-pBabe-neo and hTERT-pBabe-Hygro), has been described previously $[7,18]$. In brief, mouse CDK4 (kindly provided by Charles J. Sherr) and hTERT cDNAs were inserted into pBabe vectors [35] containing neomycin- and hygromycin-resistance genes, respectively. Additionally, loxP sites were placed internal to the long terminal repeats of the hTERT expression vector, to allow for excision of the entire expression cassette by Cre recombinase. These vectors were transfected into the Phoenix ecotropic packaging cell line using the calcium phosphate technique [36], and the virus-containing supernatant was used to infect the amphotropic packaging cell line PA317 [37] to obtain stable virus-producing cell lines after selection with 0.5 $\mathrm{mg} / \mathrm{ml}$ G418 or hygromycin (EMD Biosciences, San Diego, CA, USA). All infections were performed in the presence of $2 \mu \mathrm{g} / \mathrm{ml}$ polybrene (Sigma-Aldrich).

For infection of myoblasts, $5 \times 10^{4}$ cells were seeded in six-well dishes 24 hours before infection. Selection was started 48 hours after infection using $300 \mathrm{mg} / \mathrm{l}$ hygromycin and $400 \mathrm{mg} / \mathrm{l} \mathrm{G418}$ for 1 and 2 weeks, respectively. Depending on growth rates and infection efficiency, cells were passaged during the selection period before becoming confluent.

\section{Isolation of myogenic immortalized clones}

Immortalized populations were seeded at low densities, (50, 100, 200 or 400 cells per $100 \mathrm{~mm}$ dish). About 10 days after seeding, clones were isolated using cloning rings and seeded into 48-well dishes, followed by six well and $100 \mathrm{~mm}$ dishes. The exact time point for clone isolation was chosen to maximize the cell number and minimize cell density of individual clones, to facilitate 
growth after passage but avoid fusion of myoblasts, respectively. We estimate that clones contained 100 to 1000 cells at the time of isolation. All clones were analyzed for CD56 expression by flow cytometry (see below) and fusion potential in differentiation medium. The percentage of cell nuclei in multinucleated and/or MF20-positive cells was determined for 10 random fields after 3 or 7 days in differentiation medium.

\section{Terminal restriction fragment assay}

Terminal restriction fragment assay was performed as previously described [38].

\section{Flow cytometry}

Cells were detached with trypsin, counted, and sedimented by centrifugation, then $1.5 \times 10^{5}$ cells were resuspended in $0.2 \mathrm{ml}$ DMEM with $10 \%$ calf serum (Cosmic Calf Serum; Hyclone) containing 5\% supernatant from the hybridoma line 5.1H11 [39], which recognizes CD56 (kindly provided by Helen Blau). As a control, primary antibody was omitted. Cells were incubated for $30 \mathrm{~min}$ at room temperature, washed twice with $10 \%$ calf serum (Cosmic Calf Serum; Hyclone) in PBS, and incubated with secondary Alexa488-conjugated goat anti-mouse antibody (Invitrogen, Eugene, OR, USA) for $30 \mathrm{~min}$ at room temperature. After washing with PBS, cells were resuspended in $0.2 \mathrm{ml}$ PBS and analyzed on a flow cytometer (FACSCalibur; Becton Dickinson). A second flow cytometer (FACSAria; Becton Dickinson) was used for sorting, with $5 \times 10^{6}$ cells stained in upscaled volumes.

\section{Immunofluorescence}

Cells on gelatin-coated glass chamber slides (Thermo Scientific) were fixed with cold $\left(-20^{\circ} \mathrm{C}\right)$ ethanol for 5 minutes, air-dried, and rehydrated with PBS. After blocking with $10 \%$ calf serum (Cosmic Calf Serum; Hyclone) in PBS, slides were incubated with primary antibody (1:100 monoclonal mouse anti-desmin clone D33 (Thermo Scientific, Rochester, NY, USA) or MF20 supernatant (myosin heavy chain, 1:30; Developmental Studies Hybridoma Bank, Iowa City, IA, USA) for 1 hour at room temperature. Slides were washed three times with PBS for 5 min, each and incubated with secondary Alexa488-conjugated goat anti-mouse antibody (Invitrogen) for 1 hour at room temperature. After three washes with PBS, slides were covered with mounting medium containing 4',6-diamidino-2-phenylindole (Vectashield; Vector Laboratories, Burlingame, CA, USA) and imaged with a fluorescence microscope (Axiovert 200 M; Zeiss).

\section{Histology}

Tissues were frozen in liquid nitrogen-cooled isopentane, and cut on a cryostat. Frozen sections $(0.8 \mu \mathrm{m})$ were collected on microscope slides (Fisherbrand Superfrost Plus; Fisher Scientific), air-dried, and fixed with $4 \%$ formaldehyde in PBS for 15 minutes at room temperature. Slides were washed three times with PBS and stained with hematoxylin and eosin. Sections were imaged under a microscope (AxioImager M2, Zeiss) and images captured with a camera (Digital microscopy camera Axio Cam, ICC3, Zeiss).

\section{Acknowledgements}

We thank Kendal Hanger and Leigh Warsing for technical support. We also thank the two subjects for their generous participation in this research. This work was performed within the framework of the Senator Paul D. Wellstone Muscular Dystrophy Cooperative Research Center for FSHD, supported by National Institutes of Health grant 5U54HD060848. GS is an Ellison/AFAR Postdoctoral Fellow in Aging Research and was supported by an Erwin Schroedinger grant (project number J2737-B12) from the Austrian Science Fund.

\section{Author details}

'Department of Cell Biology, UT Southwestern Medical Center at Dallas, Dallas, TX, USA. 'Boston Biomedical Research Institute, Watertown, MA, USA ${ }^{3}$ Center for Genetic Muscle Disorders, The Kennedy Krieger Institute, Johns Hopkins School of Medicine, Baltimore, MD, USA.

\section{Authors' contributions}

KW, CPE and WEW designed this study. GS, JC, KW and JR performed the experiments and analyzed the results. GS, JC, KW, JWS and WEW wrote the manuscript. All authors read and approved the final manuscript.

\section{Competing interests}

The authors declare that they have no competing interests.

Received: 19 November 2010 Accepted: 8 March 2011

Published: 8 March 2011

\section{References}

1. van Deutekom JC, Wijmenga C, van Tienhoven EA, Gruter AM, Hewitt JE, Padberg GW, van Ommen GJ, Hofker MH, Frants RR: FSHD associated DNA rearrangements are due to deletions of integral copies of a $3.2 \mathrm{~kb}$ tandemly repeated unit. Hum Mol Genet 1993, 2:2037-2042.

2. Winokur ST, Barrett K, Martin JH, Forrester JR, Simon M, Tawil R, Chung SA, Masny PS, Figlewicz DA: Facioscapulohumeral muscular dystrophy (FSHD) myoblasts demonstrate increased susceptibility to oxidative stress. Neuromuscul Disord 2003, 13:322-333.

3. Gabellini D, Green MR, Tupler R: Inappropriate gene activation in FSHD: a repressor complex binds a chromosomal repeat deleted in dystrophic muscle. Cell 2002, 110:339-348.

4. Lemmers RJ, van der Vliet PJ, Klooster R, Sacconi S, Camano P, Dauwerse JG, Snider L, Straasheijm KR, van Ommen GJ, Padberg GW, Miller DG, Tapscott SJ, Tawil R, Frants RR, van der Maarel SM: A unifying genetic model for facioscapulohumeral muscular dystrophy. Science 2010, 329:1650-1653.

5. Dixit M, Ansseau E, Tassin A, Winokur S, Shi R, Qian H, Sauvage S, Matteotti C, van Acker AM, Leo O, Figlewicz D, Barro M, LaoudjChenivesse D, Belayew A, Coppee F, Chen YW: DUX4, a candidate gene of facioscapulohumeral muscular dystrophy, encodes a transcriptional activator of PITX1. Proc Natl Acad Sci USA 2007, 104:18157-18162.

6. Kowaljow V, Marcowycz A, Ansseau E, Conde CB, Sauvage S, Matteotti C, Arias C, Corona ED, Nunez NG, Leo O, Wattiez R, Figlewicz D, LaoudjChenivesse D, Belayew A, Coppee F, Rosa AL: The DUX4 gene at the FSHD1A locus encodes a pro-apoptotic protein. Neuromuscul Disord 2007, 17:611-623.

7. Zhu CH, Mouly V, Cooper RN, Mamchaoui K, Bigot A, Shay JW, Di Santo JP, Butler-Browne GS, Wright WE: Cellular senescence in human myoblasts is overcome by human telomerase reverse transcriptase and cyclin- 
dependent kinase 4: consequences in aging muscle and therapeutic strategies for muscular dystrophies. Aging Cell 2007, 6:515-523.

8. d'Adda di Fagagna F, Reaper PM, Clay-Farrace L, Fiegler H, Carr P, Von Zglinicki T, Saretzki G, Carter NP, Jackson SP: A DNA damage checkpoint response in telomere-initiated senescence. Nature 2003, 426:194-198.

9. Zou Y, Sfeir A, Gryaznov SM, Shay JW, Wright WE: Does a sentinel or a subset of short telomeres determine replicative senescence? Mol Biol Cell 2004, 15:3709-3718.

10. Olovnikov AM: A theory of marginotomy. The incomplete copying of template margin in enzymic synthesis of polynucleotides and biological significance of the phenomenon. J Theor Biol 1973, 41:181-190.

11. Makarov VL, Hirose Y, Langmore JP: Long G tails at both ends of human chromosomes suggest a $\mathrm{C}$ strand degradation mechanism for telomere shortening. Cell 1997, 88:657-666.

12. von Zglinicki T, Pilger R, Sitte $N$ : Accumulation of single-strand breaks is the major cause of telomere shortening in human fibroblasts. Free Radic Biol Med 2000, 28:64-74.

13. Greider CW, Blackburn EH: The telomere terminal transferase of Tetrahymena is a ribonucleoprotein enzyme with two kinds of primer specificity. Cell 1987, 51:887-898.

14. Morin GB: The human telomere terminal transferase enzyme is a ribonucleoprotein that synthesizes TTAGGG repeats. Cell 1989, 59:521-529.

15. Bodnar AG, Ouellette M, Frolkis M, Holt SE, Chiu CP, Morin GB, Harley CB, Shay JW, Lichtsteiner S, Wright WE: Extension of life-span by introduction of telomerase into normal human cells. Science 1998, 279:349-352.

16. Yang J, Chang E, Cherry AM, Bangs CD, Oei Y, Bodnar A, Bronstein A Chiu CP, Herron GS: Human endothelial cell life extension by telomerase expression. J Biol Chem 1999, 274:26141-26148.

17. Wieser M, Stadler G, Jennings P, Streubel B, Pfaller W, Ambros P, Riedl C,

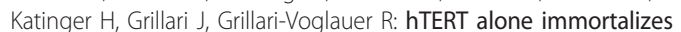
epithelial cells of renal proximal tubules without changing their functional characteristics. Am J Physiol Renal Physiol 2008, 295:F1365-1375.

18. Ramirez RD, Herbert BS, Vaughan MB, Zou Y, Gandia K, Morales CP, Wright WE, Shay JW: Bypass of telomere-dependent replicative senescence (M1) upon overexpression of Cdk4 in normal human epithelial cells. Oncogene 2003, 22:433-444.

19. Scherer WF, Syverton JT, Gey GO: Studies on the propagation in vitro of poliomyelitis viruses. IV. Viral multiplication in a stable strain of human malignant epithelial cells (strain HeLa) derived from an epidermoid carcinoma of the cervix. J Exp Med 1953, 97:695-710.

20. Todaro GJ, Wolman SR, Green H: Rapid Transformation of Human Fibroblasts with Low Growth Potential into Established Cell Lines by Sv40. J Cell Physiol 1963, 62:257-265.

21. Morales CP, Holt SE, Ouellette M, Kaur KJ, Yan Y, Wilson KS, White MA Wright WE, Shay JW: Absence of cancer-associated changes in human fibroblasts immortalized with telomerase. Nat Genet 1999, 21:115-118.

22. Dickson MA, Hahn WC, Ino Y, Ronfard V, Wu JY, Weinberg RA, Louis DN, Li FP, Rheinwald JG: Human keratinocytes that express hTERT and also bypass a p16(INK4a)-enforced mechanism that limits life span become immortal yet retain normal growth and differentiation characteristics. Mol Cell Biol 2000, 20:1436-1447.

23. Gonzalez-Suarez E, Samper E, Ramirez A, Flores JM, Martin-Caballero J, Jorcano JL, Blasco MA: Increased epidermal tumors and increased skin wound healing in transgenic mice overexpressing the catalytic subunit of telomerase, mTERT, in basal keratinocytes. Embo / 2001, 20:2619-2630

24. Stewart SA, Hahn WC, O'Connor BF, Banner EN, Lundberg AS, Modha P, Mizuno H, Brooks MW, Fleming M, Zimonjic DB, Popescu NC, Weinberg RA: Telomerase contributes to tumorigenesis by a telomere lengthindependent mechanism. Proc Natl Acad Sci USA 2002, 99:12606-12611.

25. Smith $L L$, Coller HA, Roberts JM: Telomerase modulates expression of growth-controlling genes and enhances cell proliferation. Nat Cell Biol 2003, 5:474-479.

26. Park JI, Venteicher AS, Hong JY, Choi J, Jun S, Shkreli M, Chang W, Meng Z, Cheung P, Ji H, McLaughlin M, Veenstra TD, Nusse R, McCrea PD, Artandi SE: Telomerase modulates Wnt signalling by association with target gene chromatin. Nature 2009, 460:66-72.

27. Tsivitse S: Notch and Wnt signaling, physiological stimuli and postnatal myogenesis. Int J Biol Sci 2010, 6:268-281.
28. Forsyth NR, Evans AP, Shay JW, Wright WE: Developmental differences in the immortalization of lung fibroblasts by telomerase. Aging Cell 2003, 2:235-243.

29. De Palma C, Falcone S, Pisoni S, Cipolat S, Panzeri C, Pambianco S, Pisconti A, Allevi R, Bassi MT, Cossu G, Pozzan T, Moncada S, Scorrano L, Brunelli S, Clementi E: Nitric oxide inhibition of Drp1-mediated mitochondrial fission is critical for myogenic differentiation. Cell Death Differ 17:1684-1696.

30. Bigot A, Klein AF, Gasnier E, Jacquemin V, Ravassard P, Butler-Browne $G$ Mouly V, Furling D: Large CTG repeats trigger p16-dependent premature senescence in myotonic dystrophy type 1 muscle precursor cells. Am J Pathol 2009, 174:1435-1442.

31. Li ZB, Kollias HD, Wagner KR: Myostatin directly regulates skeletal muscle fibrosis. J Biol Chem 2008, 283:19371-19378.

32. Thomas M, Langley B, Berry C, Sharma M, Kirk S, Bass J, Kambadur R: Myostatin, a negative regulator of muscle growth, functions by inhibiting myoblast proliferation. J Biol Chem 2000, 275:40235-40243.

33. Boldrin L, Muntoni F, Morgan JE: Are human and mouse satellite cells really the same? J Histochem Cytochem 2010, 58:941-955.

34. Wright WE, Shay JW: Inexpensive low-oxygen incubators. Nat Protoc 2006, 1:2088-2090

35. Morgenstern JP, Land H: Advanced mammalian gene transfer: high titre retroviral vectors with multiple drug selection markers and a complementary helper-free packaging cell line. Nucleic Acids Res 1990, 18:3587-3596.

36. Swift S, Lorens J, Achacoso P, Nolan GP: Rapid production of retroviruses for efficient gene delivery to mammalian cells using 293T cell-based systems. Curr Protoc Immunol 2001, Chapter 10(Unit 10):17C.

37. Miller $A D$, Buttimore $C$ : Redesign of retrovirus packaging cell lines to avoid recombination leading to helper virus production. Mol Cell Biol 1986, 6:2895-2902.

38. Herbert BS, Shay JW, Wright WE: Analysis of telomeres and telomerase. Curr Protoc Cell Biol 2003, Chapter 18(Unit 18):16.

39. Walsh FS, Ritter MA: Surface antigen differentiation during human myogenesis in culture. Nature 1981, 289:60-64.

doi:10.1186/2044-5040-1-12

Cite this article as: Stadler et al.: Establishment of clonal myogenic cell lines from severely affected dystrophic muscles - CDK4 maintains the myogenic population. Skeletal Muscle 2011 1:12.

\section{Submit your next manuscript to BioMed Central and take full advantage of:}

- Convenient online submission

- Thorough peer review

- No space constraints or color figure charges

- Immediate publication on acceptance

- Inclusion in PubMed, CAS, Scopus and Google Scholar

- Research which is freely available for redistribution

Submit your manuscript at www.biomedcentral.com/submit
Ciomed Central 